\title{
Uncertainty among Heart Failure Patients and its Relation to their Health Related Quality of Life
}

\author{
Aida El Sayed El Gamil, Assistant Professor \\ Medical Surgical Nursing, Faculty of Nursing, Alexandria University \\ Gihan Mohammed Ali, Assistant Professor \\ Medical Surgical Nursing, Faculty of Nursing, Cairo University \\ Mimi Mohamed Mekkawy, Assistant Professor \\ Adult Nursing, Faculty of Nursing, Assiut University
}

\begin{abstract}
Uncertainty was described as "The gap between what is known and what needs to be known in order to make correct decisions". Uncertainty has been identified as a significant part of the experience of heart disease and yet no studies have fully explored the experience of uncertainty in patients living with chronic heart failure. Objective: The study aimed to explore the uncertainty in heart failure and its relation to patient's health related quality of life (HRQOL). Setting: The study was conducted at the Out Patient Cardiac Clinic of King Abdul Aziz University Hospital in Jeddah. Subjects: A convenience sample of 60 heart failure patients were enrolled for follow up, their age ranged from 55 up to 65 years. Tools: three tools were used by the researchers to collect the necessary data: Tool I: Biosociodemogaphic characteristics tool. Tool II: Mishel uncertainty in illness scale (MUIS-C). Tool III: Health related quality of life measures (HRQOL) was used to examine disease specific HRQOL. Results: A high level of uncertainty was found in 34 (57\%) heart failure patients. The mean score of heart failure patient's uncertainty was $71+3.1$, while the mean score among patients with high and low uncertainty were $75+4.56 \& 64.5+2.88$ respectively with no significant difference. In relation to HRQOL, the overall mean score of patients was $22.3+1.7$. On the contrary, the mean score of patient's HRQOL with high uncertainty was 20.66+2.12, while the mean score of patient's HRQOL with low uncertainty was 23.63+3.61. The study clearly showed highly significant impact of uncertainty (according to F-test, $p<0.01, p<0.05$ ) on HRQOL concerning physical functioning, emotional and general health between patient's with low and high uncertainty. Low uncertainty patients had better quality of life concerning physical functioning, emotional and general health. Conclusion: The majority of heart failure patients had a high uncertainty level, which affect patient's quality of life negatively. Recommendations: It is recommended to consider the heart failure patient's uncertainty level and its negative effect on patient's quality of life as basic aspect of patient's management. Consequently the cardiac patient's health condition will be improved without further cardiac complications and repeated attacks of heart failure problems.
\end{abstract}

Keywords: Heart failure, uncertainty, health related quality of life (HRQOL).

\section{Introduction}

Heart failure is a chronic, progressive illness characterized by acute exacerbations and remissions of symptoms such as dyspnea, fatigue, cough and edema ${ }^{(1,2)}$.
These symptoms impact patients' comfort and well being as well as their ability to maintain their usual activities of daily living. Even common activities, such as walking or maintaining hygiene, can be difficult secondary to the primary symptoms of dyspnea and fatigue. Patients with heart 
failure experience high morbidity and life limiting illness while suffering from substantial physical and psychosocial burdens. There is a large unmet care needs for adults with chronic heart failure ${ }^{(3-5)}$.

Uncertainty has been identified as a significant part of the experience of heart disease and yet no studies have fully explored the experience of uncertainty in patients living with chronic heart failure ${ }^{(6,7)}$. Uncertainty was experienced during the time of initial diagnosis of heart disease, with recurrence of symptoms, when treatment decisions were being made, and when adjustments in therapies were needed.

Uncertainty is inherent in the human experience but is even more silent when one is presented with a life-threatening or chronic illness $^{(8-10)}$.

Uncertainty in illness was first proposed by Mishel $^{(11)}$ as a way to understand adjustment to acute or chronic illness, it was defined as the in ability to determine the meaning of illness - related events and occurs in situations where the decision maker is unable to assign definite values to objects and events and is unable to accurately predict outcomes because sufficient cues are lacking $^{(1)}$. Moreover uncertainty was described as "The gap between what is known and what needs to be known in order to make correct decisions". In addition uncertainty events are characterized as ambiguous, vague, unpredictable, unclear, and lacking information which limits the patient's ability to choose coping process. Uncertainty provide useful information that can be utilized by health care professionals to plan and implement educational and supportive programs and provide counseling that meets the specific needs of these patient $^{(12-15)}$.

Uncertainty explains how patients construct meaning related to their illness utilizing cognitive processes. The symptom pattern in heart failure provokes uncertainty because of the ambiguity in presentation and insidious onset, this uncertainty was related to the life-threatening nature of cardiac problems and raised fear of invalidism continuing damage to the heart, and death. Cardiovascular patients were also found to perceive uncertainty about the effectiveness of treatment related to their inability to clearly connect the treatment to specific outcomes ${ }^{(16)}$. There is sufficient evidence that uncertainty has a negative impact on quality of life and psychosocial adjustment in chronic illness. Patients with heart failure have difficulty in discerning pertinent symptoms, endure frequent hospitalizations, and have self care needs that require diligent self-monitoring and multiple medications to maintain an acceptable quality of life (QOL) ${ }^{(17,18)}$.

Health related quality of life (HRQOL) reflects the functional effect of an illness and its therapy from the patient's point of view. Poor HRQOL has been associated with poorer outcomes, such as lower survival rates, increased number of hospitalizations, decreased capacity to perform activities of daily living and decreased compliance with treatments in cardiac patients ${ }^{(19,20)}$. Despite a growing interest in HRQOL in cardiac patients, it has received little attention in heart failure. Although evidence indicates that illnessrelated uncertainty is an important concern in heart failure patients, the relationship between uncertainty and other psychological disturbances and to overall HRQOL has not been investigated ${ }^{(21-23)}$.

The sources of uncertainty in heart failure are primarily related to the changing or ambiguous symptom pattern, changes in treatment and concern regarding the quality of life. Patients with heart failure experience periods of stability and exacerbations. The difficulty lies in distinguishing progression of symptomatology from what occurs with some consistency or secondary to duration of disease ${ }^{(24-26)}$.

The significance of this research for the nursing profession is that the findings will provide a better understanding of 
uncertainty experienced by the patient with heart failure that may assist nurses of how to best help patients cope more effectively.

Moreover nurses need to be aware of the degree and nature of uncertainty in heart failure patients in order to identify nursing interventions that might alter uncertainty. Gaining knowledge of uncertainty with those patients will facilitate communication between the nurse and patients ${ }^{(27,28)}$.

Besides, the researchers are interested in exploring this area in order to add to the body of nursing knowledge concerning uncertainty and quality of life in relation to heart failure.

\section{Aim of the Study}

The aim of the study is to:

Explore uncertainty among heart failure patients and its relation to their health related quality of life.

\section{Research Question:}

What is the relationship between uncertainty and health related quality of life among heart failure patients?

\section{Materials and Method}

\section{Materials}

Design: A descriptive correlative design was used.

Setting: This study was conducted at the Out Patient Cardiac Clinic of King Abdul Aziz University Hospital in Jeddah, This clinic provides a service for cardiac patients for follow up or check up 2 days, morning and evening shift per week.

Subjects: Subjects comprised a convenience sample of 60 heart failure patients attended the previously mentioned setting for routine follow up and the last hospital admission more than 4 weeks, their age 55 to 65 years.

Tools: Three tools were used by the researchers to collect the necessary data:
Tool I: Biosociodemogaphic

\section{characteristics tool}

It was developed by the researcher and it included: patient's age, sex, marital status, educational level, number of previous admissions related to heart failure status, history of angina or chest discomfort, history of diabetes and hypertension.

\section{Tool II: Mishel ${ }^{(11)}$ uncertainty in illness} scale (MUIS-C)

It was developed in 1984 as a modification of 33- item of Mishel uncertainty in illness scale (MUIS-A). (MUIS-C) was used to measure uncertainty in community of chronically ill adults including non hospitalized heart disease patients. This instrument consisted of 23 items that rated patients on a 5 - point Likert scale ranging from 1 (strongly disagree) to 5 (strongly agree). Scores on the scale range from 23 to 115 , with the mid range score of 69. Scores on the scale ranging from $23-<69$ indicate low perceived uncertainty. Scores on the scale ranging from 69-115 indicate high perceived uncertainty. After a thorough review of (MUIS-A) and (MUIS-C), the MUIS was adapted by the researchers to emerge four factors from the 23 items of MUIS scale. First; ambiguity (unclear or ever changing bodily cues about the state of illness that may be confused with other illness concerns) included 10 items. Second; complexity (difficulty understanding one's treatments or the health care system) included 4 items. Third; inconsistency (incongruence between the present and prior illness experience) it included 5 items. Lastly; unpredictability (likely to change suddenly and without reason and therefore not able to be predicted) included 4 items.

\section{Tool III: Health related quality of life (HRQOL)}

It was used to examine disease specific HRQOL. It included 36 items that were used to measure 4 subscales; physical functioning (with 10 items), social role functioning (with 6 items), emotional role 
(with10 items) and general health (with10 items). The sub items included: questions about health such as; does your health now limit your activities? How much of the time has your health interfered with your social activities?.

The scale score ranged from $0-30$, the higher score indicated a higher quality of life. The cronbach coefficient was $0.94^{(6)}$. The data was collected using Arabic version.

\section{Method}

- An official permission was obtained from the managers and authorities of the Out Patient Cardiac Clinic, after explanation of the nature and objectives of the study.

- The questionnaire was developed by the researcher and translated into Arabic by the researchers and the content validity of the questionnaire was tested by a panel of five academic nursing staff experts in the study field. The needed modifications of some Arabic words were done. Contents of the tools were tested regarding to the knowledge accuracy, relevance and competence. In addition, content validity was done also for the proposed protocol to test its consistency, accuracy, applicability, relevance and feasibility

- The reliability of the MUIS-C \& HRQOL were tested using Cronbach's alpha, the values were 0.85 and 0.70 respectively.

- Pilot study was carried out on six patients, those patients were not included in the sample, to ascertain the clarity and the applicability of the tools. Modifications in the wording of the colloquial Arabic were done based on the findings of this pilot study.

- Procedure:
- Sampling was started and completed within 5 months.

- Purpose of the study was explained to the patients who agreed to participate in the study prior to data collection.

- The researchers started to collect the data from the patient after follow up visit in the outpatient clinic.

- Data were collected over a period of five months from October 2011 February 2012.

\section{Ethical considerations:}

- All patients were informed about the study purpose and their rights to decide whether or not to participate in the study. Then a written informed consent was obtained from each patient who agreed to participate in the study.

- Privacy and confidentiality of the collected data was assured.

\section{Statistical Analysis}

After completion of data collection, the data were entered into statistical package for social science (SPSS) software package version 18.0. Data were presented using descriptive statistics, $t$ test and analysis of variance (ANOVA) test was used. Pearson correlation analysis was used to identify the inter-relationships between variables. Finally, analysis and interpretation of data were conducted.

\section{Results}

Table (1) shows that the majority of patients $42 \%$ were in age group $60 \leq 65$ years old. As regard patient's sex 58\% were males. About $67 \%$ of patients were married. In relation to level of education $33 \%$ were university graduates and $17 \%$ were illiterate, on the other hand $58 \%$ had high school education and 42 had less than high school education. Furthermore $38 \%$ of 
patients were previously admitted in the hospital with heart failure and had a history of angina or chest discomfort. About 33\% and $25 \%$ were hypertensive and diabetic respectively.

Table (2) represented biosociodemographic characteristics in relation to level of uncertainty; it was found that $34(57 \%)$ of heart failure patients had high level of uncertainty. The lowest mean of low level of uncertainty was $60 \pm 4.3$ were among age group $55<60$, while the mean of low level and high level of uncertainty among heart failure male patients were $51.75 \pm 11.58 \quad \& \quad 71 \pm 3.1$ respectively. As regards educational level, there were statistical significance difference between patients with low and high level of uncertainty among heart failure patients were educational level less than high school education $61 \pm 4.1$ and $74 \pm 0.54$ respectively. As regards hypertensive patients, there was a statistical significant difference between patients with low and high level of uncertainty $54 \pm 3.2$ and $70 \pm 0.55$ respectively.

Table (3) points out that all heart failure patients had high uncertainty level with mean score $71 \pm 3.1$, while the majority of patients $56 \%$ with high mean score uncertainty $75+4.56$ and $43 \%$ of patients with low level of uncertainty $64.5 \pm 2.88$ with significant difference between low and high level of uncertainty groups . In relation to health related quality of life (HRQOL) the mean score of heart failure patients was $22.3 \pm 1.7$, on the contrary the mean score of patient's HRQOL with high uncertainty was $20.66 \pm 2.12$, while the mean score of patient's HRQOL with low uncertainty was $23.63 \pm 3.61$. Also it was apparent that there was an inverse relation between HRQOL and uncertainty, when uncertainty level increased patients' HRQOL became worse, and vice versa.

Table (4) shows that $30 \%$ of patients were diagnosed as heart failure patients less than six months with mean score of HRQOL 20+1.41 and mean score of uncertainty were $77 \pm 7.9$, while only $8 \%$ of patients were diagnosed as heart failure patients three to four years ago with mean score of HRQOL $23 \pm 2.37$ and mean score were $54 \pm 3.1$, moreover there was a statistical significant difference of mean scores of HRQOL and level of uncertainty in relation to time since the diagnosis of heart failure. It was obvious that the more the time elapse since diagnosis of heart failure, the better the HRQOL and uncertainty among heart failure patients.

Table (5) illustrates that the mean score of HRQOL among low and high groups of uncertainty were $25 \pm 3.9$ and $20 \pm 3.7$ respectively. The study clearly showed highly significant impact of uncertainty on HRQOL concerning physical functioning, emotional and general health between patient's with low and high uncertainty (according to f-test, $\mathrm{p}=0.001, \mathrm{p}=0.000, \mathrm{p}=$ 0.017 respectively). It was found that low uncertainty patients had better quality of life concerning physical functioning, emotional and general health.

Table (6) shows the means of items for each factor. It indicates that uncertainties related to unpredictability 3.25 and ambiguity in the situation 2.43 were highest, while the lowest uncertainties were inconsistency, however the results presented that ambiguity concerns indistinctive of the unclear or ever changing bodily cues about the state of illness that may be confused and tend to blur and overlap with other illness concerns. Also the lack of contingency between illness and treatment cues and illness outcome (unpredictability) are the main cause of high uncertainty among heart failure patients.

Table (7) pointed out that uncertainty (MUIS.C) the correlations were significant at $\mathrm{p}<0.05$ and $\mathrm{p}<0.01$ for 12 of the 23 items, however it revealed that these 12 items represent the uncertainty among heart failure patients.

Table (8) illustrates the correlations of heart failure patients' quality of life scores 
of physical functioning, social role functioning, emotional role and general health, it revealed that physical functioning had weak positive significant correlations with general health $(\mathrm{r}=0.33)$, social role functioning $(\mathrm{r}=37)$ and emotional role $(r=0.38)$. Moreover, the results indicate that the emotional role had a strong positive significant correlation with social role functioning $(\mathrm{r}=0.86)$.

Table (9) illustrates the correlation of heart failure patients' uncertainty scores of ambiguity, complexity, inconsistency and unpredictability. It revealed that ambiguity had a strong positive significant correlations with inconsistency $(\mathrm{r}=87)$, it means that patients' uncertainties related to ambiguity is a causative factor for high uncertainty among heart failure patients.

Table (10) presents the correlation of HRQOL and uncertainty factors, it was found that HRQOL had a strong positive significant correlations with ambiguity $(\mathrm{r}=0.28)$, secondary inconsistency $(\mathrm{r}=0.26)$. It means that uncertainties related to ambiguity and inconsistency had a negative effect on patients' quality of life.

\section{Discussion}

Uncertainty may be appraised as a threat related to an individual's in ability to determine what is at stake. Alternatively, uncertainty may be appraised as an opportunity, allowing the individual to formulate positive interpretations of the meaning of an event; it may have a positive influence on patients and may facilitate hope that patients' illness is not severe as feared. The concept of quality of life is an adaptational outcome of particular interest with cardiac patients ${ }^{(22)}$. A number of authors have attempted to delineate the components that should be included in the description and measurement of quality of life for cardiac patients. Quality of life was identified in terms of functional capacity, symptoms and their consequences, perceptions of health status and satisfaction with life. Living with uncertainty, change, conflict and tremendous personal and medical issues, also it meant moving between periods of certainty and uncertainty ${ }^{(20)}$.

Uncertainty was experienced when information was lacking or usual care failed and as a result individuals fluctuated between feeling in control and feeling out of control. No studies have been found which examine the relationship between uncertainty and quality of life in heart failure patients, however this study was done looking at relation between uncertainty and health related quality of life among heart failure patients ${ }^{(22)}$.

The results of present study revealed that the majority of heart failure patients age were sixty years old and more, this may be attributed to the increased prevalence of heart failure in patients over sixty years of age, this is in live with American heart association reports that heart failure is the most common admission diagnosis in the United States for patients over sixty years of age. Moreover it was found that more than half of heart failure patients were those with high school education, this is in line with Christopher and Cynthia ${ }^{(27,28)}$ who stated that, more than half of patients living with severe heart failure finished high school education. From the present study it was found that one third of patients was hypertensive while only one quarter was diabetic. In this respect Christopher and Cynthia $^{(29)}$ found that only twenty one of patients living with severe heart failure complained of diabetes and hypertension. Concerning the relation of patient's biosociodemographic characteristics to uncertainty, the study presented that more than half of heart failure patients had low uncertainty (score > 69) while less than half of the patients had high uncertainty (score $>69$ ).

This can be attributed to the fact that, heart failure patients attend the outpatient cardiac clinic on regular time and they are provided with individualized patient 
counseling. This is supported by JO-ann ${ }^{(30)}$ who stated that it is possible that counseling would have facilitated the reduction of uncertainty. Moreover the study results were confirmed by Ahadi B. et $\mathrm{al}^{(31)}$ who mentioned that heart disease patient's uncertainty is increased when insufficient information about the symptoms and the disease control are provided and they think that their symptoms may worsen. Also their results showed that, there was a positive relationship between uncertainty and increased score of depression in cardiac patients which lead to imbalance in the activity of the sympathetic and parasympathetic systems, increased heart rate and blood pressure, and stimulated muscles ability of the heart to increase and cause disturbance in heart rhythm and heart will follow it.

The study showed that the age group $55<60$ had low uncertainty while the age group $50<55$ had high uncertainty this result may be related to the fewer responsibilities and obligations in the former age group. This finding agrees with $\mathrm{JO}-\mathrm{ann}^{(30)}$ who explained that the low level of uncertainty may be related to the older adults who may have reached the developmental stage where they believe they have completed the major part of their life work and have lived their lives well.

The present study showed that single and male patients had higher uncertainty than married which may be related to loneliness and increased responsibilities. This is supported by Winter ${ }^{(9)}$ who stated that, social support was particularly important during times of illness exacerbation, when activity of daily living were disturbed, and when making and carrying out treatment decisions, patients recognized the significant role family members played in providing support.

The study revealed that there was a significant relation between low and high uncertainty in relation to less than high school education, patients had low uncertainty actually, this could be explained by the ability of the patient to retain and search about information related to their disease. In addition, patients with previous heart failure hospital admission had low uncertainty with no significant relation between high and low uncertainty as well as significant relation regarding heart failure patients complaining of diabetes, this is supported by Qiu, et $\mathrm{al}^{(32)}$ who stated that patients may feel that the health care system will provide the necessary care in the future, should they need it.

It was evident from the results of the study that heart failure patients' health related quality of life was affected by uncertainty, and high uncertainty in particular is significantly related to changes in patients' thoughts and behaviors that evolved over time in response to changes in their heart. This in contrast with Eastwood ${ }^{(6)}$ who reported that, uncertainty can be viewed as either danger or opportunity, when positive inferences are made, uncertainty perceived as an opportunity. Conversely perceptions of danger arise when negative inferences are made; uncertainty therefore triggers a new perspective on life and influence health related quality of life.

The findings of the present study have shown that patients with six months to less than one year time since diagnosis of heart failure had a significant decrease in HRQOL with increased uncertainty. This may be due to instability of patient health condition during this period with increased ability to recognize and respond to symptoms, and being changed from thinking about their disease most of the time during diagnosis, treatment, and periods of exacerbation, to rarely thinking about it during times of stability. These findings are in accordance with several studies ${ }^{(20-24)}$ that mentioned uncertain times challenged patients' ability to put thoughts of their heart disease in the background ${ }^{(21)}$. Uncertainty was experienced during the time of initial diagnosis of heart disease, with recurrence of symptoms, when 
treatment decisions were being made, and when adjustments with therapies were needed.

The current findings also presented that high uncertainty had adverse effect on health related quality of life $(\mathrm{Mean} \pm \mathrm{SD}=$ $20 \pm 3.7$ ), with poor HRQOL subscale emotional role general health, physical functioning and social role finding, where all mean scores were lower than the mean scores of HRQOL subscale of low uncertainty patients with a significant relation to all except social role functioning $^{(3)}$. Our findings provide relative contribution of patients' emotional, general health, physical and social subscale to HRQOL in heart failure patients in relation to uncertainty level, thus heart failure patient is likely to experience marked reductions in aspects of HRQOL if he has higher levels of uncertainty. This results are in line with Eastood $^{(6)}$ who reported that uncertainty about the illness is the greatest psychological stress for patients with life threatening illness, also stated that uncertainty spreads into many areas of a person's life, dismantles the meaning of everyday events, and because the stimulus for disorder.

This study has identified ambiguity as a primary construct of the illness uncertainty experienced by heart failure patients, it means that patients' responses to ambiguity such as limiting investment of energy in the future activities, acting only on information they perceive as important and favoring nonthreatening explanations of symptoms could lead to suboptimal outcomes. These results are supported by Falk $^{(20)}$ who stated that ambiguity intensifies the illness situation and makes a person more vulnerable because it limits coping processes and sense of control.

The study revealed that emotional role had a strong positive significant correlation with social role functioning in patients' quality of life. Also the findings from the study revealed that a significant positive relationship existed between uncertainty and HRQOL. These findings are supported by Jo-ann ${ }^{(30)}$ who stated that cardiac disease affects patients socially, physically and psychologically that is in terms of HRQOL. To regain the integrity of the self, a patient must reduce uncertainty.

\section{Conclusion}

Based on the findings of the present study, it can be concluded that the majority of heart failure patients had a high uncertainty level, which affect patient's quality of life negatively.

\section{Recommendations}

Based on the findings of the present study, it is recommended that:

- It is important to consider the heart failure patient's uncertainty level and its negative effect on patient's quality of life as basic aspect of patient's management. Consequently the cardiac patient's health condition will be improved without further cardiac complications and repeated attacks of heart failure problems.

- Further researches to construct and develop effective nursing interventions result in decreased uncertainty, improved quality of life, and deferral of active treatment until needed. 
Table (1): Biosociodemogrphic Characteristics of the Studied Patients.

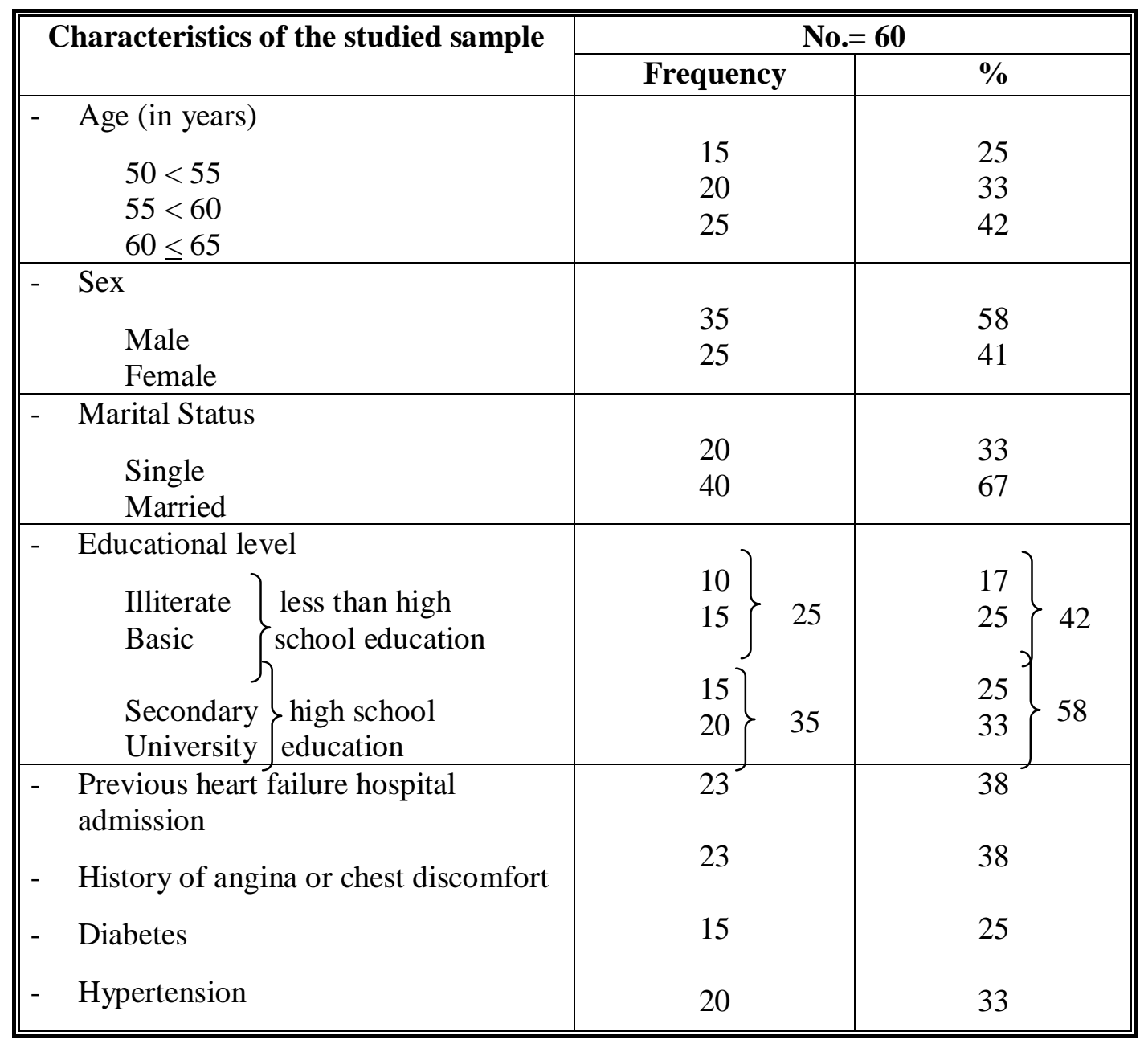


Table (2): Biosociodemogrphic Characteristics in Relation to Uncertainty.

\begin{tabular}{|c|c|c|c|c|c|c|}
\hline \multirow{3}{*}{ Characteristics } & \multirow{2}{*}{\multicolumn{2}{|c|}{$\begin{array}{c}\begin{array}{c}\text { Low uncertainty } \\
\leq 69\end{array} \\
\mathrm{n}=26(43 \%) \\
\end{array}$}} & \multirow{2}{*}{\multicolumn{2}{|c|}{$\begin{array}{c}\text { High uncertainty } \\
>69 \\
\mathrm{n}=34(57 \%) \\
\end{array}$}} & \multirow{3}{*}{ t test } & \multirow{3}{*}{ P-Value } \\
\hline & & & & & & \\
\hline & Mean & SD & Mean & SD & & \\
\hline $\begin{array}{r}\text { Age (in years) } \\
50<55 \\
55<60 \\
60 \leq 65\end{array}$ & $\begin{array}{l}68 \\
60 \\
62\end{array}$ & $\begin{array}{c}5.8 \\
4.3 \\
11.1\end{array}$ & $\begin{array}{l}80 \\
75 \\
70\end{array}$ & $\begin{array}{c}3.1 \\
4.1 \\
10.8\end{array}$ & $\begin{array}{c}0.48 \\
1.2 \\
0.59\end{array}$ & $\begin{array}{c}0.1 \\
0.235 \\
0.1\end{array}$ \\
\hline $\begin{array}{l}\text { Male } \\
\text { Female }\end{array}$ & $\begin{array}{c}51.75 \\
59\end{array}$ & $\begin{array}{c}11.5 \\
4.3\end{array}$ & $\begin{array}{l}71 \\
70\end{array}$ & $\begin{array}{l}3.1 \\
3.2\end{array}$ & $\begin{array}{l}0.92 \\
1.49\end{array}$ & $\begin{array}{l}0.215 \\
0.163\end{array}$ \\
\hline $\begin{array}{r}\text { Marital status } \\
\text { Single }\end{array}$ & 58 & 4 & 73.4 & 4.1 & 1.18 & 0.242 \\
\hline Married & 56 & 3.9 & 72 & 3.9 & 2.23 & 0.26 \\
\hline Educational level & & & & & & \\
\hline $\begin{array}{l}\text { Less than high } \\
\text { school education }\end{array}$ & 61 & 4.1 & 74 & 0.54 & 1.9 & $0.05^{*}$ \\
\hline $\begin{array}{l}\text { High school } \\
\text { education }\end{array}$ & 59.6 & 4.1 & 70 & 3.2 & 0.92 & 0.16 \\
\hline $\begin{array}{l}\text { Previous heart failure } \\
\text { hospital admission }\end{array}$ & 56 & 3.8 & 72 & 0.53 & 1.3 & 0.17 \\
\hline $\begin{array}{l}\text { History of angina or chest } \\
\text { discomfort }\end{array}$ & 60 & 4.2 & 77 & 8.8 & 0.97 & 0.334 \\
\hline Diabetes & 59 & 4.1 & 70 & 0.55 & 1.6 & $0.05^{*}$ \\
\hline \begin{tabular}{|l} 
Hypertension \\
\end{tabular} & 54 & 3.2 & 70 & 0.53 & 1.3 & 0.198 \\
\hline
\end{tabular}

$* *$ indicates $\mathrm{p}<0.01$

$*$ indicates $\mathrm{p}<0.05$ 
Table (3): Distribution of Studied Patients' Scores in Health Related Quality of Life and Uncertainty.

\begin{tabular}{|c|c|c|c|c|}
\hline \multirow[t]{2}{*}{ Health related measures } & \multicolumn{2}{|c|}{ Uncertainty score } & \multirow[t]{2}{*}{$\mathrm{t}$ - test } & \multirow[t]{2}{*}{ P-value } \\
\hline & Mean & SD & & \\
\hline Patient's Uncertainty $n=60$ & 71 & 3.1 & & \\
\hline $\begin{array}{l}\text { High uncertainty patients } n=34 \\
(57 \%)\end{array}$ & 75 & 4.56 & \multirow[t]{2}{*}{1} & \multirow[t]{2}{*}{$0.001^{*}$} \\
\hline \multirow[t]{3}{*}{$\begin{array}{l}\text { Low uncertainty patients } n= \\
26(43 \%)\end{array}$} & 64.5 & 2.88 & & \\
\hline & \multicolumn{2}{|c|}{ HRQOL score } & & \\
\hline & Mean & SD & & \\
\hline Patient's HRQOL $n=60$ & 22.3 & 1.7 & & \\
\hline High uncertainty patients $n=34$ & 20.66 & 2.12 & \multirow[b]{2}{*}{0.50} & \multirow[b]{2}{*}{$0.001^{*}$} \\
\hline Low uncertainty patients $n=26$ & 23.63 & 3.61 & & \\
\hline
\end{tabular}

* indicates $\mathrm{p}<0.05$

Table (4): The Relationship between Time since Diagnosis of Heart Failure, Health Related Quality Of Life and Uncertainty.

\begin{tabular}{|c|c|c|c|c|c|c|c|}
\hline \multirow{2}{*}{$\begin{array}{c}\text { Time since } \\
\text { diagnosis of heart } \\
\text { failure }\end{array}$} & \multirow[b]{2}{*}{ No \% } & \multicolumn{2}{|c|}{ HRQOL } & \multicolumn{2}{|c|}{ Uncertainty } & \multirow[b]{2}{*}{ F. Test } & \multirow{2}{*}{$\begin{array}{c}\mathbf{P} \\
\text { Value }\end{array}$} \\
\hline & & Mean & SD & Mean & SD & & \\
\hline$<6$ months & 30 & 20 & 1.41 & 77 & 7.9 & -171.5 & $0.001^{*}$ \\
\hline 6 months to $<1$ year & 25 & 19.33 & 1.21 & 73 & 4 & -188 & $0.001^{*}$ \\
\hline 1 to $<2$ years & 10 & 23 & 3.66 & 60 & 4.1 & -31.97 & $0.001^{*}$ \\
\hline 2 to $<3$ years & 12 & 22 & 2.73 & 62 & 4.2 & -50.73 & $0.001^{*}$ \\
\hline 3 to $\leq 4$ years & 8 & 23 & 2.37 & 54 & 3.1 & -31.13 & $0.001^{*}$ \\
\hline
\end{tabular}

** indicates Significant Fisher FP $<0.01$;

* indicates Significant Fisher FP $<0.0$ 
Table (5): Mean score and Standard Deviation of Heart Failure Patients, Health Related Quality of life with low And High Uncertainty.

\begin{tabular}{||l|c|c|c|c|c|c||}
\hline \multirow{3}{*}{ Health related measures } & \multicolumn{2}{|c|}{$\begin{array}{c}\text { Low } \\
\text { Uncertainty } \\
\mathbf{2 6}(\mathbf{4 3 \%})\end{array}$} & \multicolumn{2}{c||}{$\begin{array}{c}\text { High } \\
\text { Uncertainty } \\
\mathbf{3 4 ( 5 7 \% )}\end{array}$} & \multirow{2}{*}{ F-test } & \multirow{2}{*}{ P-Value } \\
\cline { 2 - 7 } & Mean & SD & Mean & SD & & \\
\hline - HRQOL & 25.3 & 3.9 & 20 & 3.7 & 3.114 & 0.078 \\
\hline - Physical Functioning & 23 & 2.5 & 21 & 1.88 & 7.068 & $0.001^{*}$ \\
\hline - Social Role Functioning & 25.21 & 4.1 & 22 & 3.6 & 03.108 & 0.088 \\
\hline - Emotional Role & 22 & 2.3 & 19 & 03.24 & 2.224 & $0.000 * *$ \\
\hline - General Health & 24 & 4.3 & 20 & 8.52 & 05.73 & $0.0172 *$ \\
\hline
\end{tabular}

Table (6): Mean score and Standard Deviation of Uncertainty factors.

\begin{tabular}{||l|c|c|c|c||}
\hline \hline Factor & $\begin{array}{c}\text { Items in } \\
\text { Factor }\end{array}$ & $\begin{array}{c}\text { Mean of } \\
\text { Factor }\end{array}$ & SD & $\begin{array}{c}\text { Mean of } \\
\text { items }\end{array}$ \\
\hline I Ambiguity & 10 & 36.57 & 8.79 & 2.43 \\
\hline II Complexity & 4 & 10.46 & 3.06 & 2.25 \\
\hline III Inconsistency & 5 & 7.86 & 2.45 & 2.17 \\
\hline IV Unpredictability & 4 & 16.67 & 3.05 & 3.15 \\
\hline
\end{tabular}


Table (7): Correlations for Significant Uncertainty Items of Studied Sample.

\begin{tabular}{|c|c|c|c|}
\hline $\begin{array}{l}\text { Item } \\
\text { No. }\end{array}$ & Item & $\begin{array}{l}\text { Correlation } \\
\text { coefficient (r) }\end{array}$ & Significance (p) \\
\hline 16 & The results of my tests are inconsistent. & .782 & $.001 * *$ \\
\hline 1 & $\begin{array}{l}\text { Because of the treatment, what I can do } \\
\text { and cannot do keeps changing. }\end{array}$ & .775 & $.001 * *$ \\
\hline 2 & I have a lot of questions without answers. & .792 & $.001 * *$ \\
\hline 7 & $\begin{array}{l}\text { My symptoms continue to change } \\
\text { unpredictably. }\end{array}$ & .728 & $.001 * *$ \\
\hline 10 & My treatment is too complex to figure out. & .827 & $.001 * *$ \\
\hline 1 & I don't know what is wrong with me. & .886 & $.001 * *$ \\
\hline 9 & $\begin{array}{l}\text { The doctors say things to me that could } \\
\text { have many meanings. }\end{array}$ & .546 & $.001 * *$ \\
\hline 3 & $\begin{array}{l}\text { I am unsure if my illness is getting better } \\
\text { or worse. }\end{array}$ & .637 & $.001 * *$ \\
\hline 11 & $\begin{array}{l}\text { The doctors say things to me that could } \\
\text { have many meanings. }\end{array}$ & .588 & $.001 * *$ \\
\hline 6 & $\begin{array}{l}\text { The purpose of each treatment is clear to } \\
\text { me. }\end{array}$ & .462 & $.001 * *$ \\
\hline 20 & $\begin{array}{l}\text { The treatment I am receiving has a known } \\
\text { probability of success. }\end{array}$ & .327 & $.020 *$ \\
\hline 22 & The results of my tests are inconsistent. & .348 & $.020 *$ \\
\hline
\end{tabular}

*Significance: $\mathrm{p}<.05,{ }^{* *} \mathrm{p}<.01$ 
Table (8): Correlations of Health Related Measures of Heart Failure Patients' Quality of Life Sub Scale.

\begin{tabular}{||l|c|c|c|c||}
\hline \multicolumn{1}{|c|}{ HRQOL } & $\begin{array}{c}\text { Physical } \\
\text { functioning }\end{array}$ & $\begin{array}{c}\text { Social Role } \\
\text { functioning }\end{array}$ & $\begin{array}{c}\text { Emotional } \\
\text { role }\end{array}$ & $\begin{array}{c}\text { General } \\
\text { health }\end{array}$ \\
\hline Physical functioning & 1.00 & & & \\
\hline Social Role functioning & $0.37 *$ & 1.00 & & \\
\hline Emotional role & $0.38^{*}$ & $0.86 *$ & 1.00 & \\
\hline General health & $0.33^{*}$ & $0.21 *$ & $0.18^{*}$ & 1.00 \\
\hline
\end{tabular}

*Significance: $\mathrm{p}<.01$

Table (9): Correlations of studied Sample in Uncertainty Factors.

\begin{tabular}{||l|c|c|c|c||}
\hline \multicolumn{1}{|c|}{ Measures } & $\begin{array}{c}\text { MUIS } \\
\text { ambiguity }\end{array}$ & $\begin{array}{c}\text { MUIS } \\
\text { complexity }\end{array}$ & $\begin{array}{c}\text { MUIS } \\
\text { inconsistency }\end{array}$ & $\begin{array}{c}\text { MUIS } \\
\text { unpredictabilit } \\
\mathbf{y}\end{array}$ \\
\hline $\begin{array}{l}\text { MUIS } \\
\text { (ambiguity) }\end{array}$ & 1.00 & 0.49 & $0.87^{* *}$ & 0.03 \\
\hline $\begin{array}{l}\text { MUIS } \\
\text { (complexity) }\end{array}$ & 1.00 & $0.56^{* *}$ & $0.28^{*}$ \\
\hline $\begin{array}{l}\text { MUIS } \\
\text { (inconsistency) }\end{array}$ & & 1.00 & -0.06 \\
\hline $\begin{array}{l}\text { MUIS } \\
\text { (unpredictability) }\end{array}$ & & & & 1.00 \\
\hline
\end{tabular}

** indicates $\mathrm{p}<0.01 \quad *$ indicates $\mathrm{p}<0.05$

Table (10): Correlations of Health Related Quality Of Life and Uncertainty Factors among studied Sample.

\begin{tabular}{||l|c|c|c|c|}
\hline \hline Measures & $\begin{array}{c}\text { MUIS } \\
\text { ambiguity }\end{array}$ & $\begin{array}{c}\text { MUIS } \\
\text { complexity }\end{array}$ & $\begin{array}{c}\text { MUIS } \\
\text { inconsistency }\end{array}$ & $\begin{array}{c}\text { MUIS } \\
\text { unpredictabilit } \\
\mathbf{y}\end{array}$ \\
\hline HRQOL & $-0.28^{*}$ & $-0.18^{*}$ & $-0.26^{* *}$ & -0.06 \\
\hline \hline
\end{tabular}

** indicates $\mathrm{p}<0.01 \quad *$ indicates $\mathrm{p}<0.05$ 


\section{References}

1. Remme W, Swedberg K. Task Force for the Diagnosis and Treatment of Chronic Heart Failure Guidelines for the diagnosis and treatment of chronic heart failure. Europe Heart Journal 2001; 22:1527-60.

2. Mousa A, Ahmed M, Laila M. Zaheya A, Hayudini J. Psychological experiences and quality of life in patients awaiting coronary artery bypass graft. International Journal of Advanced Nursing Studies, 2014, 3 (1) 47-52.

3. Greco V, Derek R. Uncertainty, stress, and health. Personality and Individual Differences, 2003, 34 (6): 1057-68.

4. Sampalis J, Boukas S, Liberman M, Reid T \& Dupuis G. Impact of waiting time on the quality of life of patients awaiting coronary artery bypass grafting. Canadian Medical Association Journal, 2001, 165: 429-33.

5. Cleland J, Cohen A, Cosin J. An International Survey of the Management of Heart Failure in Primary Care. The Improvement of Heart Failure Programme. Lancet. 2002, 360:1631-9.

6. Eastwood J, Doering L, Roper J, Hayes R D. Uncertainty and health Related quality of life 1 year after coronary angiography. American Journal of Critical Care, 2008, 7: 232-42.

7. Jong D. Watt W. Arthur H. Anxiety and health-related quality of life in patients awaiting elective coronary angiography. Heart and Lung, 2004, 33: 237-48.

8. Giammaco D, Gitto L.Quality of life and uncertainty in illness for chronic patients' .Mediterranean Journal of Clinical Psychology, 2014, 2 (2): 24052.

9. Winters C. Heart failure: Living with uncertainty. Cardiovascular Nurse, 1999, 14(3): 85-91.
10. Piliae RE, Molassiotis A. An exploration of the relationships between uncertainty, psychological distress and type of coping strategy among Chinese men after cardiac catheterization. Journal of advanced nursing, 2001; 33(1): 79-88.

11. Bialey DE, Latini DM, Hegarty J, Caroll PR, Klein EA, Albesten PC. Measuring illness uncertainty in men undergoing active surveillance (AS) for prostate cancer. Applied Nursing Research, 2011, 24 (4): 193-99.

12. Cormick K, Naimark B, Tate $R$. Uncertainty, symptom distress, anxiety, and functional status in patients awaiting coronary artery bypass surgery. Heart Lung, 2006, 35: 34-45.

13. Lari M, Packham C, Gray D. Patients' satisfaction and quality of life in coronary artery disease. Health Qual Life Outcomes, 2003, 1: 57.

14. Carney RM, Freedl KE, Rich MW and Jaffe AS. Depression as a risk factor for cardiac events in established coronary heart disease: A review of possible mechanisms. Annals of Behavioral Medicine, 1995; 17(2): 142-9.

15. Miranda R, Mennin D. Depression, generalized anxiety disorder, and certainty in pessimistic predictions about the future. Cognitive Therapy Research, 2007; 1(31): 71-82.

16. Khourdi I, Zeggwagh A, Abidi K, Madani N \& Abouqal R Measurement properties of the short form 36 healthrelated quality of life after intensive care in Morocco. Acta Anaesthesiologica Scandinavia, 2007, 51: 189-97.

17. Mosterd A, Cost B, Hoes W. The prognosis of heart failure in the general population: The Rotterdam Study. Europe Heart Journal, 2001; 22(13):1827.

18. Krumholz M, Parent M. Readmission after hospitalization for congestive heart failure among medicare beneficiaries. 
Archive of Internal Medicine, 1997; 157:99-104.

19. Cowie R, Wood A, Coats J. Survival of patients with a new diagnosis of heart failure: a population based study. Heart, 2000; 83:505-10.

20. Falk k, Swedberg K, Johansson G, Ekman I. Fatigue is a Prevalent and Severe Symptom Associated with Uncertainty and Sense of Coherence in Patients with Chronic Heart Failure. Europe Journal of Cardiovascular Nursing, 2007, 6 (2): 99-104.

21. ZambroskiaC, Moserb D, Bhatc G, Zieglerd C. Impact of Symptom Prevalence and Symptom Burden on Quality of Life in Patients with Heart Failure. Europe Journal of Cardiovascular Nursing, 2005, 4 (3): 198-206.

22. Lee K, Connor C. Long-term quality of life and uncertainty in patients living with an implantable cardioverter defibrillator. Heart \& Lung: The Journal of Acute and Critical Care, 2005, 34 (6): 386-92.

23. Heo S, Moser D, Riegel B Hall L, Christman N.Testing a Published Model of Health-Related Quality of Life in Heart Failure. Journal of Cardiac Failure, 2005, 11 (5): 372-9.

24. Peter J, Mattias A, Dahlströma B, Anders B .Measurement of HealthRelated Quality of Life in Chronic Heart Failure, from a Nursing Perspective-a Review of the Literature . Europe Journal of Cardiovascular Nursing, 2004, 3 (1): 7-20.
25. Britz J, Dunn K. Self-care and quality of life among patients with heart failure. Journal of the American Academy of Nurse Practitioners, 2010, 22 (9): 480-7.

26. Lari M, Packham C, Gray D. Unmet health needs in patients with coronary heart disease: implications and potential for improvement in caring services. Health Qual Life Outcomes, 2003; 1:26.

27. Bosworth B, Siegler C, Olsen K. Social support and quality of life in patients with coronary artery disease. Qual Life Research, 2000, 9(7):829-39.

28. Fowers J. Perceived control, illness status, stress, and adjustment to cardiac illness. Journal of Psychology, 1994; 128:567-76.

29. Christopher C, Cynthia M.A. Descriptive study of the partner's experiences of living with severe heart failure. Heart Lung, 2011, 40(3):208-16.

30. JO-ann E, Uncertainty over time and its relationship to life satisfaction for biological valve patients. Published Master thesis faculty of graduate studies school of nursing, British Colombia University, 1989:59-79.

31. Ahadi B, Narimani M, Sooreh J. Depression and Uncertainty in Cardiac Patients. Zahedan Journal of Research in Medical Sciences, 2012, 14(10): 103-6.

32. Qiu YG, Zheng LR, Chen JZ, etal. Psychological status and their influencing factors in patients suspected of coronary disease before and after coronary catheterization [in Chinese]. Zhonghua Liu Xing Bing Xue Za Zhi. 2003, 24(3):224-8. 